\title{
Representaciones sociales de un grupo de docentes de la Ciudad de México sobre la evaluación del desempeño docente
}

\author{
Social Representations of a Group of Mexico City Teachers Facing
} their Performance Evaluation

Yazmín Margarita Cuevas Cajiga ${ }^{1}$

\section{Resumen}

En 2013, el Estado mexicano anunció una reforma educativa cuyo eje rector era la evaluación del desempeño docente, proceso mediante el cual se regula el ingreso a la profesión, la permanencia en el servicio, la promoción a puestos de dirección escolar y la asignación de estímulos económicos. Sin embargo, en México el gremio docente tiene una trayectoria singular, dado que la carrera de los profesores de primaria se cimentó en un sistema que consideraba la antigüedad y la actualización profesional como requisitos para obtener y conservar un puesto definitivo. Este artículo plantea la siguiente pregunta: ¿Cómo interpretan e incorporan un grupo de profesores de educación primaria de la Ciudad de México la evaluación del desempeño docente que se propone en la reforma educativa 2013? Para responderla se tomó como marco de referencia la teoría de las representaciones sociales, se asumió el enfoque metodológico cualitativo, se diseñó una entrevista semiestructurada que se realizó a 12 maestros de una zona escolar de la Ciudad de México. Así, en las entrevistas se encontró que para el profesorado la evaluación representa la posibilidad de perder su puesto de trabajo, por lo cual toman medidas para aprobar un examen, no para actualizarse o formarse con el objetivo de mejorar su práctica.

\section{Palabras clave}

Docentes, evaluación docente, desempeño docente, organismos internacionales, representaciones sociales, educación básica.

\section{Abstract}

In 2013, the Mexican state announced the implementation of an educational reform that relied on the principle of teaching performance to regulate admission to the profession, retention in service, promotion to school management positions and the attribution of financial incentives. In Mexico, however, the teacher's union have a unique system in which seniority and teacher training were considered as the only requirements to obtain a job and keep it. This article intends to find an answer to the following question: How do teachers interpret and assimilate the teaching performance assessment system implemented by the 2013 education reform? In order to do so, the author took as a reference framework the theory of social representations. The study was based on a qualitative methodological approach. The author drew up a semi-structured interview to 12 teachers who belonged to a specific school area of Mexico City. The interviews show that to them the assessment symbolizes the possibility to lose their job. Teachers take measures to pass the exam, not to train or to improve their practice.

\section{Key words}

Teachers, teacher evaluation, teaching performance, international organizations, social representations, elementary school. 


\section{Representaciones sociales de un grupo de maestros de la Ciudad de México sobre la evaluación del desempeño docente}

Los organismos internacionales tienen un lugar muy importante en la definición de planes y acciones en los sistemas educativos nacionales (Lingard y Sellar, 2013). En este sentido, a partir de mediados de la década de 2000, organismos como el Banco Mundial (BM), la Organización para la Cooperación y el Desarrollo Económicos (OCDE) y la Organización de las Naciones Unidas para la Educación, la Ciencia y la Cultura (UNESCO) han enfatizado el lugar del profesorado en el logro del aprendizaje del alumnado y, por consecuencia, en el incremento de la calidad de la educación básica. Estos organismos, con algunas modificaciones, recomiendan tres grandes acciones a los sistemas de educación básica: perfeccionar los sistemas de selección de aspirantes a ingresar a la profesión docente, fortalecer la formación del profesorado con programas flexibles, activos y continuos e incorporar procesos de evaluación docente ligados a la contratación y al otorgamiento de estímulos económicos (UNESCO, 2014; Bruns y Luque, 2014 y OCDE, 2005).

Si bien estos organismos no dictan al pie de la letra las políticas educativas nacionales, sí sugieren conceptos, modelos y estrategias de implementación en la política educativa que marcan e influyen, de alguna manera, a los docentes, la evaluación y la enseñanza, por mencionar algunos aspectos. Sin embargo, la incorporación de políticas internacionales, formuladas para escenarios ideales, tiene que modificarse y adaptarse de acuerdo con cada contexto y sistema educativo, con lo cual estas políticas toman cursos particulares e imprevistos (Lingard y Sellar, 2013). Por su parte Ball (2012) señala la necesidad de hacer una distinción clara entre la política que se pretende llevar a cabo, producto de las ideologías oficiales, la política efectiva constituida por textos que sistematizan las reglas de implantación y la política en uso (realpolitik), que se compone por las prácticas y los discursos de los actores que la aplican.

En este sentido, la intención de este artículo es desvelar las políticas de uso de la evaluación del desempeño docente de un grupo de maestros de educación primaria de la Ciudad de México. Por ello partimos de 2008, año en que México y la OCDE firmaron un acuerdo para mejorar la calidad de la educación básica que involucraba seguir acciones encaminadas a la rendición de cuentas del personal docente (OCDE, 2011). En seguida, en 2013 la Secretaría de Educación Pública (SEP)² anunció una reforma educativa que tuvo como eje rector la evaluación del desempeño docente, proceso por el cual se regula el ingreso a la profesión, la permanencia en el puesto, la promoción a cargos de dirección escolar y la asignación de estímulos económicos. Ahora bien, hay que tener presente algunas particularidades, en primer lugar la carrera de los profesores se definía por criterios de antigüedad y actualización como únicos requisitos para obtener y conservar un puesto definitivo. Hasta 2013, en México la regulación de la profesión docente era de corte credencialista, es decir que se basaba en la acumulación de certificaciones y en el cumplimiento de años de servicio (Cuenca, 2015). Además, el Sindicato Nacional de Trabajadores de la Educación (SNTE) tenía una participación más que considerable en este sistema, en función de que todos los profesores de educación básica nacional están obligados a pertenecer a este Sindicato. Además, sus funciones y acciones están supeditadas a cuestiones extra educativas como movilizaciones políticas, apoyo a tal o cual candidato político, activismo, entre otras. Sin embargo, con la reforma 2013 se modificaron radicalmente esas condiciones de contratación docente al implantar un sistema de evaluación del desempeño con carácter obligatorio, dirigido a la rendición de cuentas. Es razonable suponer, entonces, que el profesorado no

2 Que en México es la institución encargada de la educación básica pública, equivalente al Ministerio de Educación, Cultura y Deporte español. 
asumiría dócilmente ni de manera mecánica e inmediata esta evaluación, sino que requerirían de hacer un esfuerzo para aceptarla, de valerse de filtros, por llamarlos de algún modo, que permitan asimilarla.

En este estudio se planteó la siguiente pregunta de investigación: ¿Cómo interpretan e incorporan un grupo de profesores de educación primaria de la Ciudad de México la evaluación del desempeño docente propuesta con la reforma educativa $2013 ?^{3}$ Para responderla se tomó como marco de referencia la teoría de las representaciones sociales y se desarrolló un estudio de corte cualitativo. La intención de este texto no es generalizar sus resultados a todo el país, sino documentar algunas de las voces de los protagonistas de la política de evaluación del desempeño: el profesorado.

Este artículo se estructura en cuatro apartados: el primero presenta el sustento teórico de la investigación y sus coordenadas metodológicas; el segundo expone las condiciones situacionales que permiten comprender las interpretaciones que hace el profesorado sobre la evaluación del desempeño; en el tercero se explica la representación social sobre la evaluación del desempeño docente que construyeron los entrevistados; en el cuarto y último se discuten los resultados.

\section{Apoyo teórico y coordenadas metodológicas del estudio}

Se consideró que la teoría de las representaciones sociales es una vía analítica adecuada para este estudio, ya que atiende a las elaboraciones de sentido común de los actores. Mediante las representaciones sociales los actores asimilan e interpretan los sucesos u objetos desconocidos o que suponen un conflicto para los actores (Moscovici, 1979). Entonces, constituyen sistemas de interpretación donde entran en juego las opiniones, los conocimientos y las creencias (Rateau, 2016). Puesto que las representaciones sociales se crean y recrean de manera colectiva, la inscripción del actor a un grupo determinado tiene alta injerencia en la conformación y contenido de las mismas (Jodelet, 1989). En este artículo se recupera el concepto de representación social de Jodelet (1986: 472) quien explica que «son imágenes que condensan un conjunto de significados; sistemas de referencia que nos permiten interpretar lo que sucede, e incluso, dar sentido a lo inesperado; categorías que sirven para clasificar las circunstancias, los fenómenos y a los individuos con quienes tenemos algo que ver». Las representaciones sociales como conocimientos de sentido común son socialmente útiles porque, por un lado, permiten a los actores asimilar la realidad social; por otro, orientan sus prácticas.

Una representación se compone por un objeto que es propio de algo o alguien, que provoca alteración social, discusión y debate entre los actores (Jodelet, 1989). Las fuentes de construcción de las representaciones sociales son un conjunto de condiciones sociales, históricas y culturales particulares.

Para el desarrollo de la investigación se asumió una aproximación metodológica cualitativa, ya que ofrece un acercamiento al objeto de estudio en su complejidad y en su contexto cotidiano (Flick, 2004). Este enfoque se ocupa por sacar a la luz las maneras de pensar y actuar de actores y grupos (Jodelet, 2003). En este estudio no se pretende afirmar que todo el profesorado piensa igual con respecto a la evaluación del desempeño docente, por el contrario, al emplear el enfoque cualitativo se parte de que estos actores construyen representaciones sociales diferenciadas en relación con sus repertorios culturales y sociales. Así, adoptar una postura cualitativa se contrapone a la generalización de resultados de investigación. Nuestra intención es, más bien, documentar y reconocer la diversidad de significados y prácticas

3 Este artículo deriva de los trabajos del proyecto de investigación «La reforma educativa vista por sus actores. Un estudio en representaciones sociale» (número de registro 220691), que cuenta con financiamiento del Consejo Nacional de Ciencia y Tecnología (CONACYT) de México. 
que llevan a que la política tome tantas posibilidades de aplicación.

Se eligió la entrevista semiestructurada para la recolección de representaciones sociales, ya que destaca por su carácter abierto y flexible que permite el acercamiento a las percepciones, actitudes, creencias y valoraciones de los actores. Asimismo, se diseñó una guía de entrevista con el propósito de descubrir el contenido de la representación social.

Al ser un estudio de corte cualitativo se formó un grupo de informantes a fin de adentrarse en su subjetividad y evidenciar a profundidad las concepciones, emociones y actitudes que desencadena sobre ellos la evaluación del desempeño docente. Se determinaron dos criterios de selección de los participantes del estudio: a) formar parte del profesorado de educación primaria pública, b) acceder de forma voluntaria a ser entrevistado. Se realizaron doce entrevistas a maestros de la Ciudad de México. Cada una de éstas se transcribió y, posteriormente, se hizo un análisis temático (Rodríguez et al., 1999), que dio lugar a la construcción de categorías de análisis que a su vez se vincularon con el marco teórico (objetivación y el anclaje) para establecer conexiones con los datos empíricos.

\section{Contexto del surgimiento de la representación social: el escenario de ruptura}

Antes de presentar el análisis de los resultados es necesario exponer las condiciones de ruptura que supuso para el profesorado la evaluación del desempeño docente, lo que permitirá comprender el contexto del surgimiento de la representación social.

En México, desde la década de 1920, el control y el financiamiento de la educación básica pública es una de las responsabilidades del Estado, lo que ha dado ciertas características particulares a la educación primaria y a su profesorado. A partir de 1944 la formación del profesorado y su contratación estuvo a cargo de la SEP (Mercado, 2002). El proceso consistía en ingresar a la escuela normal y ser contratado automáticamente tras la conclusión de los estudios, aunque de forma temporal, durante seis meses y un día después del término de los cuales se obtenía una plaza definitiva que se convertía en propiedad exclusiva y vitalicia de su poseedor. Hasta antes de 2013 no existieron procedimientos académicos o administrativos para ratificar la pertenencia a estos puestos. Incluso se permitía que se heredaran o vendieran plazas docentes (OCDE, 2011 y Arnaut, 1998). Si se deseaba ocupar el cargo de director o supervisor escolar, el aspirante debía acumular antigüedad y presentar documentos que probaran que había tomado cursos de actualización docente, lo cual era revisado por una comisión (donde participaba la SEP y el SNTE), para valorar la movilidad del puesto (Diario Oficial de la Federación, 1973).

En 1993, como parte de las políticas de mejora de la calidad, la SEP, en colaboración con el SNTE, puso en funcionamiento un programa de evaluación docente voluntario asociado a la entrega de estímulos económicos: la Carrera Magisterial. El mecanismo fundamental de este programa era la presentación de un examen y la acreditación de actualización continua del profesorado mediante cursos. Pocos ingresaron a este programa, además de que la injerencia del SNTE en la toma de decisiones era significativa por lo que su puesta en marcha y el logro de sus propósitos han sido bastante discutidos (Santibáñez et al., 2007).

Un aspecto esencial que debemos señalar que en México el profesorado de educación básica, y particularmente el de primaria, de manera obligatoria está afiliado al SNTE, el cual ha tenido un papel protagónico como mediador entre el gremio magisterial y el Estado, principalmente con dos fines: el primero, para que el profesorado obtuviera puesto de trabajo permanentes y aumentos salariales; el segundo para 
cohesionar al profesorado en favor de los intereses del gobierno en turno. Ornelas señala que a través de las organizaciones sindicales el Estado mexicano «asignaba pactos de subordinación de los trabajadores a la estructura del Partido [Revolucionario Institucional] ${ }^{4}$ y lealtad al presidente orientados a mantener el orden social, la legitimidad del Estado y el consenso para el sistema» (Ornelas, 2008: 450). Con diferentes grados de intervención esta organización se consolidó como una entidad que agrupaba, representaba y ejercía el control del gremio. La razón principal de este hecho es que una parte de los puestos docentes eran asignados por dicho Sindicato.

En 1979 dentro del SNTE surgió una corriente disidente de maestros que se organizó en la Coordinadora Nacional de Trabajadores de la Educación (CNTE) con el objetivo de democratizar las decisiones sindicales y mejorar las condiciones de trabajo del gremio (Muñoz, 2008). Los docentes que se agrupan en la CNTE han sido críticos a la política educativa de México. Esta organización tiene una gran presencia en los estados de Guerrero, Oaxaca, Michoacán y Chiapas, pero también cuenta con simpatizantes en toda la República Mexicana. Así, el sistema de educación primaria en México, sobre todo las regulaciones de la docencia, necesita ser entendido tomando en cuenta la relación Estado-SNTE-profesorado, que ha trazado una organización particular.

En 2010 la OCDE publicó el documento Mejorar las escuelas. Estrategias para la acción en México (OCDE, 2010), donde se presentaron pautas de política educativa para la evaluación docente de México ${ }^{5}$. En 2013 se llevaron a cabo tales recomendaciones mediante la instauración de una reforma educativa, donde por primera vez se contemplaba la evaluación del desempeño docente:

«El establecimiento del criterio del mérito profesional como la base para poder ingresary avanzar en el ejercicio de la profesión docente implica un nivel de calidad que se traduzca en transparencia, certidumbre y universalidad en el trato (se refiere a la validez y operación del sistema para toda la población docente) como las nuevas reglas del juego de la profesión docente». (Bracho y Zorrilla, 2015:33)

Así, México propuso, como punto focal de la evaluación docente, la capacidad individual del profesorado, cuyos logros personales serán los que le permitirán conservar su trabajo y avanzar en su carrera profesional. Con este propósito, la SEP creó el Servicio Profesional Docente y concedió la autonomía al Instituto Nacional para la Evaluación de la Educación (INEE). En 2014 aparecieron los Perfiles, parámetros e indicadores para docentes (SEP, 2014) que marcaban los criterios a seguir en esta evaluación.

La evaluación del desempeño docente regula cuatro procesos:

1) El ingreso a las plazas docentes, que es abierto para todos los egresados de educación superior (incluyendo a quienes asistieron a las escuelas normales) los cuales deben presentar un examen de opción múltiple. Al aprobarlo el profesorado novel ocupa un puesto temporal por dos años. Una vez que finaliza este periodo nuevamente presenta una evaluación que, de ser aprobada, les otorgará una plaza por cuatro años (Diario Oficial de la Federación, 2013).

2) La permanencia en la plaza docente, cada cuatro años el profesorado está obligado a presentar una evaluación docente para refrendar su puesto de trabajo (Diario Oficial de la Federación, 2013). Para

4 El Partido Revolucionario Institucional (PRI) gobernó a México por más de setenta años.

5 Cuevas y Moreno (2016) realizaron un estudio donde contrastaron las recomendaciones que la OCDE (2010) hizo a México respecto de la evaluación docente con las acciones que siguió este país en la reforma educativa 2013. En sus resultados reportan que México atendió tales orientaciones estratégicas, principalmente la elaboración de estándares docentes y la creación de un sistema de evaluación mediante el cual se designan plazas docentes, se ratifica la permanencia en el sistema educativo, se determinan las promociones a puestos de dirección escolar y se otorgan estímulos salariales. 
Cordero y Luna (2014): «en la reforma constitucional la novedad ha sido el concepto de permanencia, tema que ha despertado inconformidad de los profesores» (p.81). Esto se debe a que cada maestro tiene un máximo de tres oportunidades para aprobar la evaluación, de no hacerlo será retirado de su puesto de trabajo.

3) La promoción del maestro a puestos de dirección escolar, que demanda, además de acumulación de experiencia docente, la presentación de un examen y un periodo de observación de dos años para que se le asigne al aspirante la función directiva (SEP, 2015b).

4) Los incentivos al salario docente, encaminados a maestros que obtengan resultados excepcionales en la evaluación de la permanencia.

Una vez que fue aprobada la reforma educativa y en particular la evaluación del desempeño docente, el profesorado organizado en la CNTE se opuso abiertamente mediante paros laborales y protestas en la Ciudad de México. Por su parte el SNTE no expresó un rechazo tajante a la medida, debido a que se apresó a Elba Esther Gordillo su líder.

De esta forma la evaluación docente que se propone con la reforma 2013 altera los derechos laborales y políticos que el profesorado, como gremio, consiguió desde hace más de siete décadas (Del Castillo, 2014). Sobre todo, esta evaluación de rendición de cuentas confronta al profesorado con nuevas formas de regulación de su carrera, basadas en un enfoque meritocrático (Cuenca, 2015), donde los valores en los que fueron formados y contratados, que les daban certitud profesional y laboral, hoy están cambiando. Así, el profesorado entrevistado se situaba en un escenario de ruptura entre un sistema que conocía y manejaba a la perfección, con requisitos cómodos y elementales, a uno donde el centro es una evaluación obligatoria y con base en méritos, que dejó fuera de las negociaciones al SNTE. Evidentemente, para el profesorado es difícil aceptar a pie juntillas esta evaluación; por el contrario, exhiben un comportamiento donde se amalgaman significados y prácticas anteriores con las nuevas que se les imponen.

\section{Características del profesorado entrevistado}

Se entrevistaron doce profesores de educación primaria de la Ciudad de México de la delegación Benito Juárez. Esta zona se caracteriza por su alta urbanización: 98\% de la población recibe los servicios de agua y drenaje, $100 \%$ tiene electricidad, $82 \%$ cuenta con acceso a internet, $80 \%$ hace uso del ordenador, $50 \%$ es propietaria de su vivienda, $98.5 \%$ de los niños de entre 6 y 11 años asiste a la educación primaria (INEGI, 2016). De acuerdo con la información proporcionada por los directores escolares de la zona, la población a la que atendían el profesorado entrevistado era hijos de empleados de gobierno y de pequeños comerciantes.

6 Personaje emblemático durante más de dos décadas en la vida política mexicana. Llegó a detentar un poder importante y su nombre era sinónimo de corrupción para el imaginario mexicano. Actualmente el SNTE pasa por un proceso de reconfiguración en su organización y propósito. En este estudio no se tienen elementos para discutir este tema. Es necesario generar investigaciones al respecto. 


\section{Tabla I. Profesorado entrevistado}

\begin{tabular}{|c|c|c|c|c|}
\hline CLAVE & SEXO & FORMACIÓN & $\begin{array}{l}\text { ANTIGÜEDAD COMO } \\
\text { MAESTRO DE PRIMARIA } \\
\text { (AÑOS) }\end{array}$ & $\begin{array}{c}\text { TIPO DE } \\
\text { CONTRATACIÓN }\end{array}$ \\
\hline M01 & Hombre & Normal Básica, Normal Superior & 35 & Permanente \\
\hline M02 & Mujer & Normal Básica & 28 & Permanente \\
\hline M03 & Hombre & Licenciatura en Educación Primaria & 7 & Permanente \\
\hline M04 & Mujer & Licenciatura en Educación Primaria & 17 & Permanente \\
\hline M05 & Mujer & Licenciatura en Educación Primaria & 9 & Permanente \\
\hline M06 & Mujer & Normal Básica & 3 & Temporal \\
\hline M07 & Mujer & Licenciatura en Educación Primaria & 8 meses & Temporal \\
\hline M08 & Hombre & Normal Básica, estudios de Arquitectura & 28 & Permanente \\
\hline M09 & Mujer & Licenciatura en Educación & 9 & Permanente \\
\hline M010 & Mujer & Normal Básica, estudios en Psicología Social & 30 & Permanente \\
\hline M011 & Mujer & Normal Básica, Licenciatura en Pedagogía & 27 & Permanente \\
\hline M012 & Mujer & Licenciatura en Educación Primaria, maestría en Desarrollo Educativo & 17 & Permanente \\
\hline
\end{tabular}

Fuente: elaboración propia a partir del análisis de las entrevistas.

De los doce profesores entrevistados (ver Tabla 1), nueve eran mujeres y tres hombres, lo que es un reflejo de la feminización de la profesión docente mexicana (Tenti y Steinberg, 2011). Salvo una profesora, los demás estudiaron en escuelas normales, es decir cuentan con una formación especializada en la enseñanza. Sin embargo, seis profesores, asistieron a la escuela normal cuando el requisito solamente era cumplir con la educación secundaria con lo que tienen una formación de nivel técnico. Cuatro de estos seis profesores cursaron posteriormente educación superior (licenciatura en educación secundaria, licenciatura en pedagogía, estudios en arquitectura y estudios en psicología). Los seis profesores restantes cuentan con licenciatura en educación primaria. Seis ostentan títulos de nivel superior como docentes, dos estudios universitarios interrumpidos, dos de normal básica y uno con el grado de maestría.

Con respecto a la antigüedad docente, cinco se destacaron por una amplia experiencia profesional en el trabajo frente a grupo (entre 35 y 27 años), dos con una trayectoria consolidada de 17 años, tres estaban fortaleciendo su conocimiento como docentes (entre siete y nueve años de antigüedad) y dos acababan de ingresar al servicio (menos de tres años), a los cuales generalmente se les denomina profesores noveles.

Ahora bien, diez profesores estaban contratados de manera permanente y dos temporalmente. En relación con la elección de la profesión docente cinco entrevistados señalaron estar influidos por su familia, cuatro indicaron que siempre quisieron ser maestros y solamente uno explicó que su decisión se basó en cuestiones de orden económico, al ser una carrera que se estudiaba en poco tiempo y con la cual se obtenía un trabajo seguro al egresar.

Los doce profesores afirmaron que, aunque obligatoriamente están afiliados al SNTE no tenían un activismo político. Solamente uno señaló tener simpatía con la CNTE, los once restantes expresaron su rechazo a esta organización.

El grupo de entrevistados se caracterizó por trabajar con una población de alumnado que tenía acceso a todos los servicios y poca desigualdad social. Además, son profesionales de la enseñanza, por lo que, 
tienen una significativa experiencia docente y seleccionaron su profesión por cuestiones de carácter personal más que económico.

\section{Representación social de la evaluación del desempeño docente: despido, miedo y estudio}

La evaluación es una actividad inherente al trabajo del profesorado con el alumnado, a la cual se le da diferentes usos dependiendo de las necesidades de su práctica, por ejemplo, como una vía para obtener información del estado del aprendizaje de su grupo o bien para emitir la acreditación de un curso. Cuando se emplea a la evaluación en el profesorado adquiere otro sentido, sobre todo en aspectos como estímulos económicos y asignación de puestos de trabajo (Isoré, 2010). ¿Cómo interpretan esto el profesorado entrevistado?, ¿Qué les es relevante?, ¿Qué acciones y posiciones toman?

Encontramos que, los participantes de la investigación elaboran una representación social de la evaluación del desempeño docente que se condensa en el miedo a la pérdida del puesto de trabajo, por lo que establecen acciones para aprobar el examen que tienen la obligación de presentar. Los procesos de ingreso a la carrera, la promoción a puestos directivos y el otorgamiento de estímulos económicos no aparecieron en su discurso. Para sustentar esta afirmación presentamos este apartado a través de dos procesos de elaboración de representaciones sociales: la objetivación y el anclaje.

\section{Objetivación: el miedo al examen}

La objetivación es un proceso que permite «materializar en imágenes concretas lo que es puramente conceptual» (Ibáñez, 2001: 186). Se compone de tres fases: la selección y la descontextualización, la formación del núcleo figurativo y la naturalización. Analizaremos cada una con detenimiento.

Selección y descontextualización. Es la recuperación que hacen los actores de la información relacionada con el objeto de representación. Es una discriminación arbitraria de ciertos datos significativos o atractivos sobre ese objeto (Jodelet, 1989 y Moscovici, 1979). En el análisis de las entrevistas se identificó que la información relevante para los actores es que la evaluación del desempeño es una política que llegó con el presidente Enrique Peña Nieto (2012-2018) ${ }^{7}$, los siguientes testimonios son ilustrativos:

«Llega el presidente nuevo y trae estructuras, reformas y cambios no meditados a la educación». (M10: 4).

"Llega cierto presidente y comenzamos a cambiar libros de texto, programas educativos, todos nos ajustamos y nos enfocamos. Acaba ese periodo [de gobierno] y se tira todo a la basura». (M01: 5)

Para dimensionar estos testimonios se debe considerar que la evaluación docente y la reforma educativa fueron propuestas que se implantaron en los primeros meses del gobierno de Enrique Peña Nieto. Por eso los entrevistados creen que la evaluación es una modificación poco estudiada y planeada, que responde más a la llegada de un nuevo gobierno que a una necesidad real del sistema educativo. Generalmente, la instauración de reformas educativas y sus acciones, como es la evaluación docente, tienen un proceso que, si bien no es prolongado, involucra etapas de discusión con los acto-

\footnotetext{
Presidente que ha personificado el retorno del Partido Revolucionario Institucional (PRI), tras doce años fuera del poder. Este partido dominó el país durante 70 años. Una de las primeras acciones de Enrique Peña Nieto como presidente fue llevar adelante la reforma educativa que nos ocupa. Su mandato comenzó en 2012 y terminará en 2018. Valga comentar que un dogma de la política mexicana es que los presidentes solo gobiernan durante seis años y no pueden reelegirse bajo ninguna circunstancia.
} 
res y solo posteriormente se da su aprobación. En México, esto fue muy limitado y parcial ya que no hubo una presentación oficial ni un documento dirigido al profesorado donde se dieran a conocer los cambios y una justificación amplia sobre la incorporación de una evaluación del desempeño docente. La descontextualización se dio respecto de la información de carácter informal, como lo ilustran los siguientes testimonios:

«Nos dicen que nos van a quitar el trabajo a todos, otros dicen que nos van a mover de puesto». (M03: 12).

«Nos quieren quitar los derechos que ya tenemos desde años atrás, nos quieren despojary se quieren valer de "Es que [el maestro] no sabe", y pues ya no te contratan». (M10: 4)

«Son leyes muy bien definidas a la conveniencia ¿de quién?, ¿del trabajador? No lo creo». (M08: 4)

En las entrevistas se observó que la evaluación para ratificar la permanencia en puestos de trabajo es un elemento al que hacen más mención el profesorado. Éstos entienden que las modificaciones legales relacionadas con la evaluación tienen el propósito de desaparecer sus derechos laborales. Los entrevistados estiman que con esta evaluación se perjudican sus derechos laborales, ya que pueden ser destituidos de su puesto de trabajo. A pesar de esto, el profesorado reconoce que la incorporación de la evaluación docente es un mecanismo conducente a la mejora de la calidad del sistema educativo:

«Hay una crisis educativa a nivel mundial y se piensa que los profesores somos los causantes y los responsables». (M06: 7)

«Tiene que ver con el logro educativo que no ha sido el esperado [...] y eso es lo que ha llevado a esas estructuras». (M12: 6)

En las entrevistas se observa que el profesorado reconoce que en la actualidad las políticas le asignan un peso relevante al desempeño docente porque está relacionado con el logro de la calidad educativa. No obstante, lo que destaca en los testimonios son los adjetivos: causantes y responsables. Estos términos tienen una carga punitiva, que apuntan al profesorado como el principal motivo de alcanzar la calidad o como el causante del rezago actual de los sistemas educativos. Para los entrevistados la crisis de los sistemas educativos o el bajo logro de la calidad tienen como origen el profesorado, lo que constituye el motivo de la evaluación del desempeño docente.

En suma, con el análisis de las entrevistas se encuentra que los participantes del estudio únicamente recuperan información de la evaluación del desempeño docente relacionada con la permanencia en su puesto y destacan tres elementos: que es una política del nuevo gobierno, que es una modificación que conlleva la pérdida de derechos laborales y que se responsabiliza al profesorado de la calidad educativa.

El núcleo figurativo. Se estructura con la selección de información que hicieron los sujetos que conforma la imagen del objeto de representación (Jodelet, 1986). Para atender a esto, dentro de las entrevistas se formuló una pregunta de carácter evocativo: «Cuando le mencionan evaluación del desempeño docente: ¿Qué imagen le vienen a la mente?». En las respuestas se hallaron dos campos semánticos, es decir un grupo de palabras que tienen un lazo de significación: examen y miedo. En relación al examen advierten: 
«Ese examen tiene el fin de sacar todo lo que no funciona». (M05: 12)

«Se me hace muy injusto: una evaluación que significa si te contrato o no te contrato». (M04: 4)

«Creo que se quiere hacer una depuración de maestros». (M12: 7)

Un rasgo que destaca en los testimonios es que equiparan la evaluación con un examen, no obstante, mientras que la primera es un proceso amplio y complejo, el segundo es un instrumento que se emplea para obtener una información y posteriormente emitir un juicio de valoración. Así, se desdibuja la evaluación docente y sus atributos, a la que el profesorado le adjudica una alta carga negativa, y traduce en una herramienta para justificar su destitución. Por lo tanto, la evaluación del desempeño docente está asociada a la eliminación y retiro de maestros del sistema de educación primaria.

El segundo elemento es el miedo, una emoción entendida como la alteración que se produce a causa de un suceso (Platin, 2014):

«¿Qué me va a pasar si llego a reprobar? Es más el miedo». (M07: 8).

«A mi me preocupa la evaluación de la permanencia en el trabajo, en mi casa tengo las responsabilidades de madre y padre de familia». (M06: 6).

«Tenemos miedo de que nos van a evaluary nos van a despedin». (M01: 10)

La evaluación docente es generadora de miedo, ya que los entrevistados consideran que peligra su estabilidad laboral y la continuidad de la que gozaban en el sistema desde su ingreso hasta el retiro. La situación se torna más compleja porque, por lo regular, la evaluación docente afecta su economía.

Esta evaluación docente se concentra en una imagen muy poderosa: el control de la asignación o retiro de puestos docentes. El profesorado entrevistado la perfila como una medición donde se debe cumplir cierto puntaje, aprobar un examen con el fin de preservar el trabajo. En este grupo se invalida la premisa de la política internacional para la cual la evaluación es un proceso que permite identificar y mejorar prácticas docentes.

Es conveniente advertir que la evaluación del desempeño docente para la permanencia en el puesto de trabajo no se limita únicamente a la presentación de un examen. Por el contrario, de acuerdo con la SEP (2015) comprende cinco fases: un informe del director escolar sobre el cumplimiento profesional del profesorado, la conformación de un expediente con cuatro trabajos del alumnado como muestra de su práctica de enseñanza, un análisis y argumentación de la selección de tales trabajos, la presentación de un examen y la elaboración de una planeación didáctica razonada. Sin embargo, en su discurso el profesorado entrevistado solamente hace referencia al examen y al miedo que les provoca.

La naturalización. Consiste en el empleo de la imagen que elaboraron los sujetos en ciertas situaciones. Ibáñez (2001: 187) apunta que: «una vez que ha quedado el núcleo figurativo tiene toda la fuerza de los objetos naturales que se imponen por sí mismos a nuestra mente. El núcleo figurativo pasa a ser un objeto que ya estaba ahí esperando a que pudiéramos percibirlo o pensarlo». En este sentido, en las entrevistas se evidencia que en el núcleo figurativo hay una emoción: miedo a la evaluación. De esta suerte, en la naturalización se comparte el temor con los compañeros y lo incierto se transforma en una situa- 
ción normal. Así, es natural que el profesorado sienta miedo a la evaluación para la permanencia por los resultados que puede ocasionar:

«El hecho de que antes tenías seguro el trabajo y abora no, pues te pone a temblan». (M03: 12).

"Los maestros sufren estrés, no duermen bien, se despiertan de madrugada, nos despertamos con el ¿qué pasa?, ¿qué voy a hacer si no tengo trabajo? [...] tienen inseguridad, tienen miedo». (M06: 9).

«El miedo es a perder su trabajo» (M11: 7).

«Tienen miedo a la manera de evaluación, porque ya no están relacionados a ésta [...] Si tengo estudios [titulo profesional] ¿por qué competir si yo ya competi?». (M07: 7).

En los testimonios se identifica que el miedo es desencadenado por una situación concreta: la posibilidad de que al no aprobar la evaluación docente se rompa con la permanencia en el trabajo. En consecuencia, los entrevistados manifiestan que sufren alteraciones físicas como insomnio, estrés, angustia y otras emociones derivadas de la incertidumbre a la evaluación docente dado que no se sabe cómo será esa evaluación. El profesorado menciona que los estudios que cursaron en la escuela normal les otorgaron las credenciales para desempeñarse profesionalmente y la evaluación docente anula esto. Además, esta evaluación es vista como la disputa por un puesto de trabajo. ¿Cómo confrontan los entrevistados el miedo y las consecuencias de la evaluación del desempeño? Eso se clarificará al revisar el proceso de anclaje.

\section{El anclaje: estudiar para aprobar un examen}

El proceso de anclaje es el enraizamiento del núcleo figurativo en el sistema de pensamiento. Se compone en la manera que las nuevas informaciones son integradas y transformadas (Jodelet, 1989). Según Ibáñez (2001: 188) el anclaje implica utilizar «las categorías que son ya conocidas para interpretar y dar sentido a los nuevos objetos que aparecen en el campo social». El proceso de anclaje comprende tres elementos: la asignación de sentido, el enraizamiento y la instrumentalización del saber (Jodelet, 1986).

La asignación de sentido. Tiene lugar cuando «el grupo expresa sus contornos y su identidad a través del sentido que le confiere a su representación» (Jodelet, 1986: 487). De tal forma, los significados en torno a la evaluación del desempeño docente derivan de la formación profesional y experiencia del profesorado entrevistado. En los testimonios se localizó que recuperan sus conocimientos especializados sobre evaluación formativa, que se articulan con la evaluación del desempeño:

"La palabra evaluación es tan amplia [...] creo que se habla más de la presentación de un examen.

Si trabajamos con alumnos nos deberian de evaluar de otra manera». (M09: 6)

"A nosotros nos piden que no evaluemos a los alumnos de la misma manera que a otros. Se me hace ilógico que a nosotros nos quieran evaluar de una sola forma». (M03: 11)

«La evaluación docente tiene que arrojar cierto resultado, pero también hay que ver cuál es el resultado en el grupo de alumnos». (M04: 3)

Como ya se ha señalado, la evaluación es un recurso natural de la práctica docente, y el profesorado 
conoce sus atributos, instrumentos y consecuencias. Por eso, en las entrevistas resalta que la evaluación es algo extenso y no puede considerarse como aplicar un examen. En los testimonios presentados es patente una crítica a la evaluación docente que se propone en la reforma educativa en función de que consideran injusto que ésta se limite a la presentación de un examen, cuando se les recomienda emplear todo tipo de instrumentos para valorar al alumnado. En efecto, la evaluación del desempeño docente no toma en consideración una parte esencial del trabajo docente: su interacción con el alumnado. Los entrevistados consideran que con un examen no se atiende a esta dimensión:

«Los resultados docentes no se ven solamente plasmados en un examen sino también en lo práctico». (M04: 5).

«Necesitamos enfocarnos más en los alumnos y menos en la evaluación del maestro». (M07: 8)

Parece evidente que la evaluación se circunscribe al dominio de conocimientos que tiene un profesor y se deja de lado las prácticas que estos profesionales consideran influyentes.

El enraizamiento, que consiste en que «el sistema de representación proporciona los marcos, las señales a través de las que el anclaje clasificará dentro de lo familiar y explicará de una forma familiar» (Jodelet, 1986: 491-492). En otras palabras, al valerse del enraizamiento, la evaluación docente se modifica en un sentido sencillo y cercano para que el profesorado la haga familiar. En este sentido, en las entrevistas se manifestó que el profesorado emplea prácticas pasadas para señalar qué van a hacer o cómo van a actuar frente a la evaluación del desempeño docente:

«Me voy a poner a estudiar». (M11: 9)

«Estoy revisando los planes y programas de estudio». (M04: 4)

«Estudiar, prepararme es lo que nos corresponde hacer». (M09: 5)

"Estudio personal. Se tiene la guia de estudio, los conceptos y de lo que se trató ese examen, la bibliografía del examen». (M07: 7)

Teniendo en cuenta que algunas actividades inherentes a la presentación de un examen son la revisión, la comprensión e incluso la memorización de los contenidos sobre los cuales versará el mismo, se encontró que los entrevistados anclan la evaluación del desempeño docente mediante una práctica de antaño, o sea estudiar para aprobar un examen y revisar la bibliografía y las guías de estudio que hay disponibles para prepararse. En los testimonios es difícil distinguir si la preparación consistirá en la memorización de los planes y programas de estudio, aunque es obvio que el profesorado quiere conservar su trabajo, y por tanto van a estudiar. No se encontró algún otro elemento que hiciera alusión a estudiar para mejorar la práctica docente.

La instrumentalización del saber. Comprende «los elementos de la representación social que contribuyen a construir relaciones sociales» (Jodelet, 1986: 487). Así, a través del objeto de representación, en este caso la evaluación del desempeño docente, se construyen o bien consolidan relaciones sociales. En las entrevistas se evidenció que el profesorado, establece o ratifica ciertas relaciones sociales para lograr su objetivo, conservar su empleo: 
«El SNTE dio un curso de marzo a julio para presentar el examen y tener mi base [permanencia]». (M06: 4)

«Estoy tomando cursos de actualización que ojalá me permitan aprobar ese examen». (M08: 10)

"He ido a cursos de actualización para ver qué bay de nuevo, qué es lo que me van a preguntar, qué es lo que debo saber». (M10: 7)

Dado que la necesidad del profesorado es aprobar el examen que se les practique, buscan alternativas, crean vínculos y grupos de estudio, ya sea organizados por el SNTE o por instituciones de educación superior privadas que les otorguen herramientas para resolver el examen con éxito. Desde luego los entrevistados se han replanteado el papel del SNTE en la regulación de la carrera docente, dado que esta organización ya no puede participar en negociaciones de políticas educativas y laborales del personal, entonces dirige sus esfuerzos a la actualización del profesorado. La constitución de nuevas relaciones sociales entre el profesorado también se observa en el hecho que, a finales de 2016, se modificaron las fases y productos de evaluación del desempeño docente. Para el ciclo 2017-2018 comenzará a operar una formación de doce semanas ofrecida por el Instituto Nacional para la Evaluación de la Educación con el objetivo de que el profesorado elabore una planeación didáctica argumentada. Como puede verse la evaluación del desempeño docente adquiere un curso inesperado: el profesorado genera estrategias y relaciones para conservar su trabajo. Para los entrevistados los más importante es aprobar el examen para su permanencia en el trabajo y harán lo necesario para conseguirlo.

\section{Consideraciones finales}

Partimos de que los organismos internacionales (BM, OCDE, UNESCO) se han dado a la tarea de insistir en la responsabilidad nodal que tienen el profesorado en los resultados del alumnado de educación básica. Ante ello han enunciado recomendaciones donde la principal característica es que los sistemas educativos incorporen evaluaciones docentes. Esto ha ocasionado que se asocie al profesorado con la evaluación y se ponga en un segundo plano otro tipo de atributos de esta figura educativa como la enseñanza, el desarrollo de aprendizajes o de estrategias didácticas. En otras palabras, los organismos internacionales en su discurso minimizan las cualidades pedagógicas del docente. La consecuencia es que, los gobiernos locales al asumir las recomendaciones internacionales desconocen muchos de los elementos que configuran la labor docente y la reducen a una relación donde el profesorado, para cumplir con sus responsabilidades profesionales, debe ser evaluado.

Por otra parte, las políticas docentes internacionales, pensadas para ser llevadas a cabo en condiciones ideales, se adaptan e implementan de manera particular por cada sistema educativo nacional lo que lleva a resultados inesperados (Lingard y Sellar, 2013). En México la evaluación del desempeño docente se ha transformado en un medio para normar y controlar la profesión docente, algo que el Estado no había hecho (Cuevas y Moreno, 2016). Esto ha llevado a que se anule la premisa de los organismos internacionales: evaluar al profesorado para lograr la calidad educativa y mejorar los aprendizajes del alumnado. Para el profesorado de este estudio, la evaluación del desempeño docente es sinónimo de regulación de la carrera docente con lo cual se atisba en el curso particular que han tomado las políticas internacionales. Bolívar (2008) advierte que esto es una burocratización de la evaluación docente que deja de lado el mejoramiento de las prácticas de enseñanza. 
En este sentido se debe decir que para los entrevistados ésta es una evaluación de alto impacto, porque al estar vinculada con la regulación de la carrera profesional se pone en peligro su contratación. Para este grupo de actores la evaluación de su desempeño produce miedo, lo que lleva a que establezcan estrategias de corto plazo, como estudiar o memorizar contenidos para aprobar un examen. Esto coincide con la tesis de Murillo (2015) quien señala que la evaluación para la rendición de cuentas ocasiona tensión, temor y desconfianza en el profesorado (Murillo, 2015). Se observa que para el profesorado que participó en el estudio la evaluación del desempeño es burocrática (Bolívar, 2008) porque se emplea para controlar su carrera profesional, en tanto que el interés de mejorar de las prácticas docentes está ausente. Esto no es responsabilidad del profesorado, sino del mismo sistema de evaluación cuyo objeto es normar a la profesión y no el mejoramiento de la enseñanza.

En México la discusión institucional sobre evaluación docente se ha basado en la rendición de cuentas y, a partir de los testimonios analizados, se constata que esto tiene consecuencias que debilitan la práctica docente. En otras palabras, privilegiar la evaluación del desempeño docente como el eje rector de la política educativa trastoca la profesión docente, ya que todo parece indicar que el futuro del profesorado profesional dependerá únicamente del puntaje obtenido en un examen. Así, se desdibuja la responsabilidad social del profesorado como formador de ciudadanos y los saberes profesionales que lo distinguen, tales como la enseñanza. Por lo tanto, es importante que se revise y valore exhaustivamente el curso que ha tenido la evaluación del desempeño docente en México y que se consideren posibilidades y alternativas donde se contemple el seguimiento y la mejora de tal práctica, dado que, si se continúa prestando atención solo a la evaluación del desempeño como variable que genera calidad educativa, estaremos asistiendo a un cambio silencioso de la profesión.

\section{Referencias Bibliográficas}

Arnaut, Alberto (1998): "Los maestros de educación primaria en el siglo XX” en Pablo Latapí (coord.): Un siglo de educación en México (tomo II). México: Fondo de Cultura Económica.

Ball, Stephen (2012). Global Education inc: New Policy Network and Neo-Liberal Imaginary. London: Routledge.

Bolívar, Antonio (2008): “Evaluación de la práctica docente. Una revisión desde España”. Revista Iberoamericana de Evaluación Educativa, 1 (2), 57-74.

Bracho, Teresa y Zorrilla, Margarita (2015): "Perspectiva de un gran reto" en Instituto Nacional para la Evaluación de la Educación (comp.): Reforma Educativa. Marco Normativo. México: LXII Legislatura Cámara de Diputados/Instituto Nacional para la Evaluación de la Educación.

Bruns, Barbara y Luque, Javier (2014). Profesores excelentes. Cómo mejorar el aprendizaje en América Latina y el Caribe. Washington: Banco Mundial.

Cordero, Graciela y Luna, Edna (2014): "El servicio profesional docente en la perspectiva de los sistemas nacionales de formación de profesores y de evaluación. El caso de México”. Revista Iberoamericana de Evaluación Educativa, 7 (2e), 75-84.

Cuenca, Ricardo (2015). Las carreras docentes en América Latina. La acción meritocrática para el desarrollo profesional. Estrategia regional sobre docentes. Santiago: OREALC-UNESCO.

Cuevas, Yazmín y Moreno, Tiburcio (2016):'Políticas de evaluación docente de la OCDE: un acercamiento a la experiencia en la educación básica mexicana". Archivos Analíticos de Políticas Educativas, 24(120), 1-24. 
Del Castillo, Gloria (2014): "El Servicio Profesional Docente: los ejes de discusión y debate" en Gloria del Castillo y Giovana Valenti (coords.): Reforma educativa. ¿Qué estamos transformando? México: FLACSO.

Diario Oficial de la Federación (1973). Reglamento de Escalafón de los Trabajadores al Servicio de la Secretaría de Educación Pública. México, 14 de diciembre de 1973.

Diario Oficial de la Federación (2013). Ley General del Servicio Profesional Docente. Diario Oficial de la Federación, México, 3 de septiembre de 2013.

Flick, Uwe (2004). Introducción a la investigación cualitativa. Madrid: Morata.

Ibáñez, Tomás (2001): “Representaciones sociales, teoría y método” en Tomás Ibáñez, (coord.): Psicología social construccionista. Guadalajara: Universidad de Guadalajara.

INEGI (2016). Panorama sociodemográfico de Ciudad de México 2015. México: Instituto Nacional de Estadística y Geografía.

Isoré, Marlene (2010). Evaluación docente: prácticas vigentes en algunos países de la OCDE y una revisión de la literatura. Santiago: PREAL/ Editorial San Marino.

Jodelet, Denise (1986): "La representación social: fenómenos, conceptos y teoría" en Serge Moscovici (coord.): Psicología Social II. Barcelona: Paidós.

Jodelet, Denise (1989). Folies et représentations sociales. Paris: Presses Universitaires de France.

Jodelet, Denise (2003): “Apercus sur les méthodologies qualitatives” en Serge Moscovici y Fabrice Buschini (coords.): Les méthodes des sciences humaines. Paris: Press Universitaires de France.

Lingard, Bob y Sellar, Sam (2013): "Globalization, Edu-Business and Network Governance: The Policy Sociology of Stephen J. Ball and Rethinking Education Policy Analysis". London Review of Education, 11 (3), 265-280.

Mercado, Laura (2002): “El docente de educación básica, representaciones sociales de su tarea profesional”. Tesis doctoral. Universidad Nacional Autónoma de México: Facultad de Filosofía y Letras.

Moscovici, Serge (1979). El psicoanálisis, su imagen y su público. Buenos Aires: Huemul.

Muñoz, Aldo (2008): "Escenarios e identidades del SNTE. Entre el sistema educativo y el sistema político". Revista Mexicana de Investigación Educativa, 13 (37), 377-417.

Murillo, Javier (2015): "De la docencia eficaz a la evaluación eficaz de la docencia" en Gilberto Guevara; Teresa Meléndez; Fausto Ramón; Hidalia Sánchez y Felipe Tirado (coords.): La evaluación docente en el mundo. México: Fondo de Cultura Económica/Instituto Nacional para la Evaluación de la Educación.

OCDE (2005). Le rôle crucial des enseignants: Attirer, former et retenir des enseignants de qualité. Paris: Publications de 1' OCDE.

OCDE (2010). Mejorar las escuelas. Estrategias para la acción en México. París: Ediciones OCDE.

OCDE (2011). Establecimiento de un marco para la evaluación e incentivos docentes: Consideraciones para México. París: Ediciones OCDE.

Ornelas, Carlos (2008): “El SNTE, Elba Esther Gordillo y el gobierno de Calderón”. Revista Mexicana de Investigación Educativa, 13 (37), 445-469. 
Plantin, Christian (2014). Las buenas razones de las emociones. Buenos Aires: Universidad General Sarmiento/ Universidad Nacional de Moreno.

Rateau, Patrick (2016): “Representaciones sociales. Un estudio de las representaciones sociales: perspectivas metodológicas" en Patricia Ducoing (ed.): La investigación: epistemologias y metodologías. México: UNAM/ AFIRSE/Plaza y Valdés.

Rodríguez, Gregorio; Gil, Javier y García, Eduardo (1999). Metodología de la investigación cualitativa. Málaga: Ediciones Aljibe.

Santibáñez, Lucrecia; Martínez, José Felipe; Datar, Ashlesha; McEwan, Patrick; Messan, Claude y Basurto, Ricardo (2007). Análisis del sistema de evaluación y del impacto del programa de estímulos docentes de Carrera Magisterial en México. California: RAND Education.

SEP (2014). Perfil, parámetros e indicadores para docentes y técnicos docentes y propuestas de etapas, aspectos y métodos e instrumentos de evaluación. México: SEP.

SEP (2015). Etapas, métodos, aspectos e instrumentos. Proceso de evaluación del desempeño docente. México: SEP.

Tenti, Emilio y Steinberg, Cora (2011). Los docentes mexicanos. Datos e interpretaciones en perspectiva comparada. México: Siglo XXI.

UNESCO (2014). Enseñanza y aprendizaje: lograr la calidad para todos. París: UNESCO.

\section{Nota biográfica}

Yazmín Margarita Cuevas Cajiga es profesora del Colegio de Pedagogía de la Facultad de Filosofía y Letras de la UNAM. Sus líneas de investigación son: reforma educativa en educación básica, representaciones sociales y educación. Actualmente dirige el proyecto La reforma educativa vista por sus actores: un estudio en representaciones sociales, con el apoyo del Consejo Nacional de Ciencia y Tecnología. Ha publicado artículos en revistas (nacionales e internacionales) y capítulos de libro sobre representaciones sociales y educación. Entre sus últimas publicaciones destaca «Políticas de Evaluación Docente de la OCDE: Un acercamiento a la experiencia en la Educación básica mexicana» en Archivos Analíticos de Políticas Educativa. 